\title{
Speed Control of Three Phase Induction Motor Using Scalar Method and PID Controller
}

\author{
Aram NASSER \\ Department of Mechatronics \\ University of Debrecen \\ Debrecen, Hungary \\ aramoo4@gmail.com
}

\author{
Dr. Peter Tamas SZEMES \\ Department of Mechatronics \\ University of Debrecen \\ Debrecen, Hungary \\ szemespeter@eng.unideb.hu
}

\begin{abstract}
- this paper presents the speed control of a three-phase induction motor using the scalar control method with PID controller. The system maintains a constant volt to frequency ratio for any change in the load. We also used vector control method and bond graph to describe the motor model, as well as its behavior. Finally, we simulated the system using Labview, where the good results of using the scalar control technique are shown.
\end{abstract}

Keywords - controller, scalar control, simulation, Labview, three-phase induction motor, Introduction

\section{INTRODUCTION}

Three phase Induction Motors (IM,) particularly squirrel cage, are known as the industry workhorses due to higher robustness, reliability and efficiency on comparison with other motor types. Because of this, one of the most pressing needs in industry is that of controlling the speed of these motors using advanced control algorithms. Two main control strategies are used to achieve the speed control of the induction motor: Vector control and Scalar control.

By, mathematically, transform the three current phases of the induction motor into two rotating current vectors, the IM can be treated like a separately excited DC motor. These vectors represent the torque and flux of the IM, which are decoupled or orthogonal in space. When the torque vector is controlled, the flux vector will not be affected, and fast transient response obtained [2]. Scalar control, however, provides a simple and practical way for the motor speed control [3]. Although scalar methodology is not very efficient in the transient state, it gives good response in the steady state. Using non-vector controlled drive schemes, obtained by direct measurement or calculation, scalar control can be used in both open loop and closed loop feedback formats.

In this paper, we discuss the use of scalar control, with PID controller, to control the speed of a three-phase induction motor. The model of the IM, which is already existed in Labview, is also explained using its equations and Bond Graph.

\section{INDUCTION MOTOR}

\section{A. Induction Motor Mdelling}

The stator's coils of a three-phase induction motor are designed to produce a rotating magnetic field, in the air gap, when applying a three-phase supply. These phases are shifted by (120) degrees from each other. As the name of the motor suggests, an electromagnetic filed is induced in the rotor, which causes a torque that makes it rotate under the Maxwell's Equations and Faraday's law of induction motors.

To make the IM's model easier to deal with, the ClarkePark transformations are used to transform the three-phase AC components into two-phase DC rotating field. This technique is called Field Orientation Control (FOC,) which provides the decoupling between the torque and flux in a similar way to the DC machine.

In order to achieve this, first we have to convert the threephase reference rotating system into a static two-phase system ( $\alpha \beta$ system) using the Clarke's transform [3].

$$
\left[\begin{array}{l}
i_{\alpha} \\
i_{\beta}
\end{array}\right]=\frac{2}{3}\left[\begin{array}{ccc}
1 & -\frac{1}{2} & -\frac{1}{2} \\
0 & \frac{\sqrt{3}}{2} & -\frac{\sqrt{3}}{2}
\end{array}\right]\left[\begin{array}{l}
i_{a} \\
i_{b} \\
i_{c}
\end{array}\right]
$$

Then, the Park's transform is used to help converting the static two-phase system ( $\alpha \beta$ system) into a rotating one (dq system) [3]:

$$
\left[\begin{array}{l}
i_{d} \\
i_{q}
\end{array}\right]=\left[\begin{array}{cc}
\cos \theta & \sin \theta \\
-\sin \theta & \cos \theta
\end{array}\right]\left[\begin{array}{l}
i_{\alpha} \\
i_{\beta}
\end{array}\right]
$$

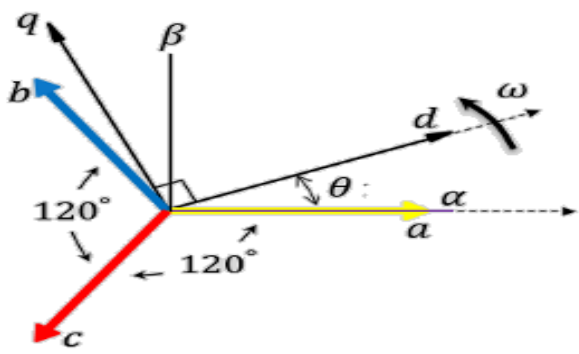


Fig. 1. The Clarke-Park rotational fields [11]

\section{B. The mathematical model}

After performing the Clarke-Park's transformations on the IM components, the flux and voltage equations, we get the two-phase components ( $\mathrm{d}$ and q.) Standard nomenclature is used to describe the IM as follows: [1]

Stator flux,

$$
\begin{aligned}
& \frac{d \varphi_{d s}}{d t}=v_{d s}-R_{s} i_{d s} \\
& \frac{d \varphi_{q s}}{d t}=v_{q s}-R_{s} i_{q s}
\end{aligned}
$$

Rotor flux,

$$
\begin{aligned}
& \frac{d \varphi_{d r}}{d t}=v_{d r}-R_{r} i_{d r}-w_{r} \varphi_{q r} \\
& \frac{d \varphi_{q r}}{d t}=v_{q r}-R_{r} i_{q r}-w_{r} \varphi_{d r}
\end{aligned}
$$

Stator currents,

Rotor currents,

$$
\begin{gathered}
\varphi_{d s}=L_{s} i_{d s}+L_{m} i_{d r} \\
\varphi_{q s}=L_{s} i_{q s}+L_{m} i_{q r}
\end{gathered}
$$

$$
\begin{aligned}
& \varphi_{d r}=L_{r} i_{d r}+L_{m} i_{d s} \\
& \varphi_{q r}=L_{r} i_{q r}+L_{m} i_{q s}
\end{aligned}
$$

Electrical torque developed by IM:

$$
T_{e}=\frac{3}{2} \frac{P}{2} L_{m}\left(i_{d r} i_{q s}-i_{q r} i_{d s}\right)
$$

The mechanical equation represents the speed, motor's torque and load, after neglecting the coefficient of friction $\mathrm{B}=0$ :

$$
J \frac{d w_{r}}{d t}=T_{e}-T_{L}
$$

Where:

- $\varphi_{d s}, \varphi_{q s}, \varphi_{d r}$ and $\varphi_{q r}$-Magnetic flux-linkage in the stator and rotor in the dq system respectively. $\left[w_{b}\right]$

- $\quad v_{d s}, v_{q s}, v_{d r}$ and $v_{q r}$-Stator and Rotor's voltages in the dq system respectively. [V]

- $\quad i_{d s}, i_{q s}, i_{d r}$ and $i_{q r}$-Stator and Rotor's currents in the dq system respectively. $[A]$

- $\quad R_{s}, R_{r}$-Stator and Rotor's resistors. [ $\left.\Omega\right]$

- $L_{s}, L_{r}$ and $L_{m}-$ Stator, Rotor and mutual inductances of the motor. $[H]$

- $J$ : Moment of inertia. $\left[\mathrm{kg} \cdot \mathrm{m}^{2}\right]$

\section{CONTROL METHOD}

\section{A. Scalar Control}

One possible way to change the speed of an IM is to vary the supply frequency, which results in the change of impedances. The decrease or increase of impedances contributes to the change of current, thus changing the torque generated by the motor. When the current decreases, the torque of the motor decreases as well. To compensate the current decrease, we have to increase the supply voltage. When the voltage increases or the frequency decreases, the coil can be burned. To avoid this problem, a constant air gap flux should be maintained at the steady state by varying the supply voltage and frequency at the same time. This technique is called the $\mathrm{V} / \mathrm{Hz}$ or scalar control method. A Proportional-IntegralDeferential (PID) controller is used to trace the slip speed and lead the motor to the steady state.

According to the equation of the induced voltage, the $\mathrm{V} / \mathrm{Hz}$ constant control gives constant flux in the stator: [5]

Where:

$$
\frac{v_{e, r m s}}{f}=(4.44) \cdot N \cdot \varphi_{s} \cdot \xi
$$

- $\quad v_{e, r m s}$-Induced voltage in the stator. [V]

- $f$-Frequency of the supplied voltage. $[\mathrm{Hz}]$

- $\quad N$ - Number of turns.

- $\varphi_{s}$ - Magnetic flux-linkage in the stator. $\left[w_{b}\right]$

- $\quad \xi$ - Constant of the coil.

The torque-speed equation of induction motors (14) can be used to determine the voltage-torque and frequency-torque functions [5]. It can be seen from (14) the inverse relationship between torque and frequency, while voltage is directly proportional to torque.

$$
T_{\text {air-gap }}=\frac{3}{2 \omega_{m}} \cdot I_{r}^{2} \cdot \frac{R_{r}}{s}
$$

Where:

- $T_{\text {air-gap }}$-The motor's torque in the air-gap. [N.m]

- $\omega_{m}$-Mechanical angular speed. $[\mathrm{rad} / \mathrm{s}]$

- $\quad I_{r}$-Rotor current. $[A]$

- $\quad R_{r}$-Resistance of rotor. $[\Omega]$

- $\quad s$-The slip. $[\mathrm{rad} / \mathrm{s}]$

Torque-speed control can be solved by the linear variation of two parameters (15) [5]:

$$
\frac{T}{\omega} \sim \frac{v^{2}}{2 \pi f^{2}} \sim \frac{v}{f}
$$

There are three speed ranges in the $\mathrm{V} / \mathrm{Hz}$ profile as shown in fig. 2: 


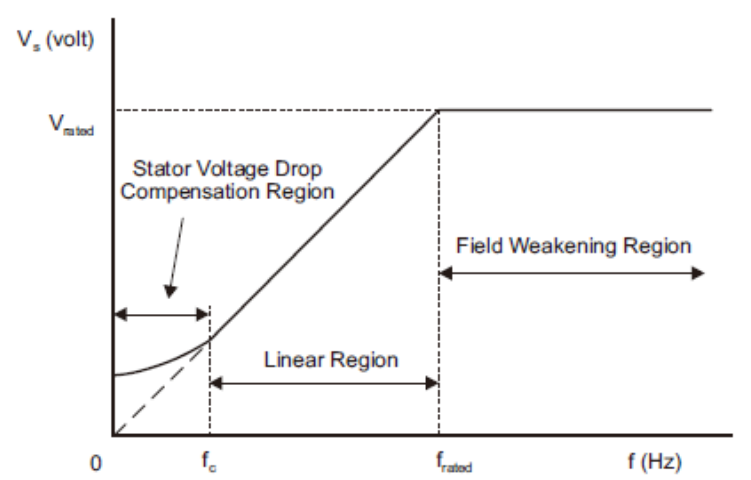

Fig. 2. Stator Voltage Versus Frequency Profile Under V/Hz Control [6]

For low frequencies, between zero (0) and cut off (fc) frequency, the stator resistance cannot be neglected and more stator voltage is needed. This increase in the voltage results in a non-linear relation between the frequency and the voltage. For high frequencies, above rated frequency, the voltage cannot be increased to maintain a constant $\mathrm{V} / \mathrm{Hz}$ ratio to avoid burning the motor's coils. This region is usually so called "fieldweakening region".

The relationship between the torque and slip speed is shown in fig. 3. It can be seen that the torque, as well as the speed of the motor, can be controlled with the constant $\mathrm{V} / \mathrm{Hz}$ principle by regulating the slip speed.



Fig. 3. Torque versus Slip Speed of an Induction Motor with Constant Stator Flux [6]

\section{Simulation SySteM}

\section{A. Bond Graph}

The Bond Graph is an effective way to describe the dynamic behavior and power flow of the IM. In order to simplify the graph, we described the dynamic structure of the motor after making the Clark-Park's transform on the IM equations. The Motor has an electromagnetic flow from the stator to the rotor, which was represented as a transformer. Then, within the Rotor, the power is converted into a mechanical one, taking into consideration the load torque as an input for the system. This power conversion is described as a gyrator that depicts the power transformation from electrical to mechanical. The analysis of induction motor system by using bond graph also lays a good foundation for the dynamic digital simulation of Labview system later.



Fig. 4. Bond graph of three phase induction motor [4]

\section{B. Labview Simulation}

Motor simulation with the parameters:

Inductances: $L_{m}=2, L I_{s}=0.15, L I_{r}=0.15[\mathrm{H}]$

Resistances: $R_{S}=0.03, R_{r}=0.03[\Omega]$

Mechanical part: $\mathrm{J}=0.15\left[\mathrm{~kg} \cdot \mathrm{m}^{2}\right]$, coefficient of friction $B=0$

PID gains: $K_{P}=5, K_{I}=0.3$ and $K_{D}=0.3$

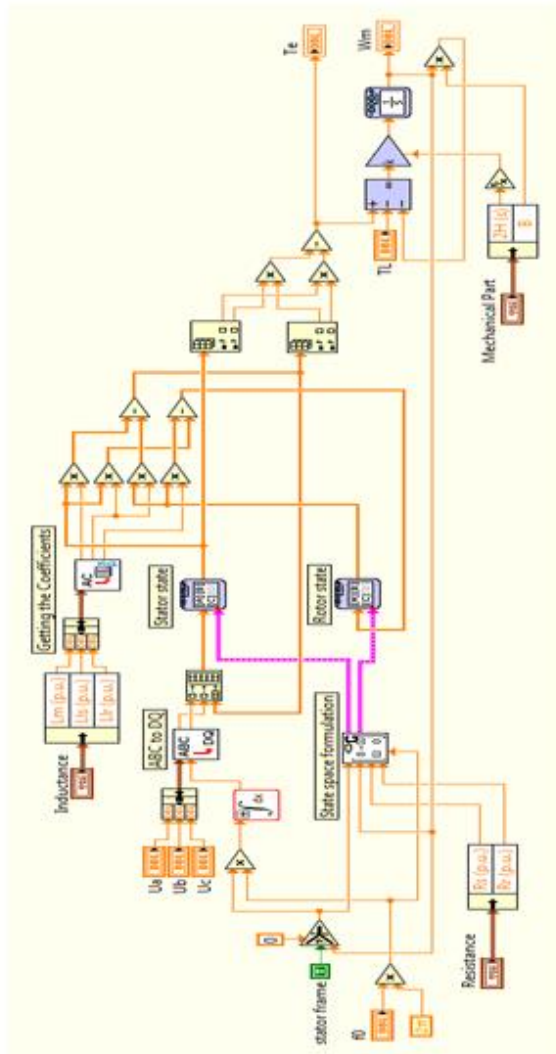

Fig. 5. Motor model

The simulation illustrates the use of the slip speed in controlling the speed of the rotor. We suppose that the motor's speed is measured by a tachometer and sent to the controller. 
The slip speed is then obtained mathematically by subtracting the actual motor speed from the synchronous one. The slip speed is manipulated by a PID controller and used to generate the values of both the voltage and the frequency. These two values are then sent to the three phase generator, in reality an inverter, to supply the stator with the controlled output, keeping a constant voltage to frequency ratio.

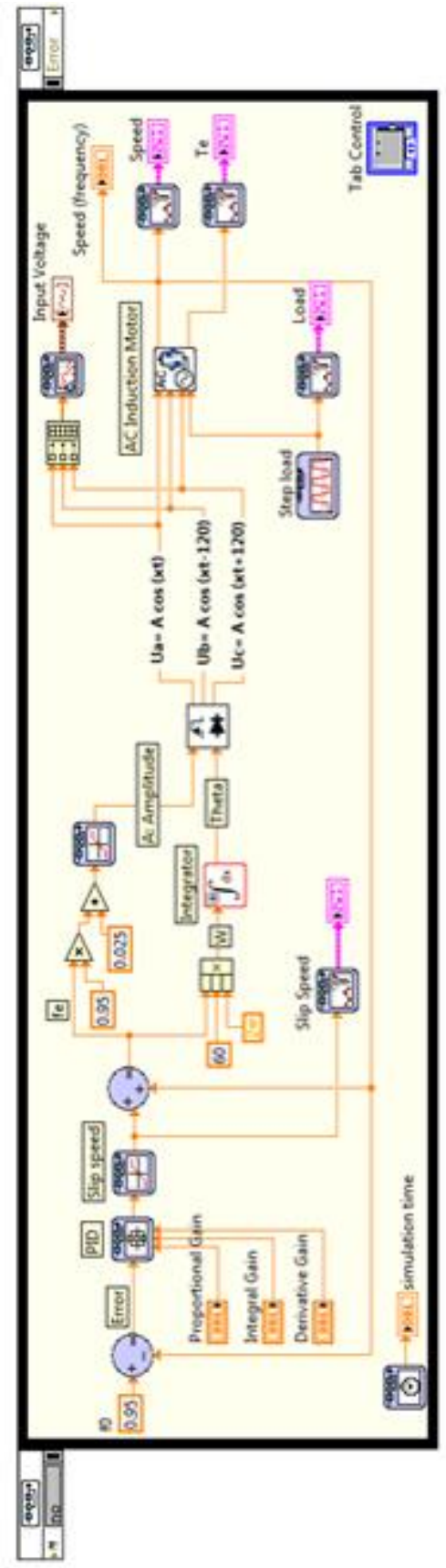

Fig. 6. System simulation

As a result of this simulation, we can notice that the amplitude and the frequency of the voltage source increase as the motor speed increases, reaching the steady state in less than one minute, fig. 7.

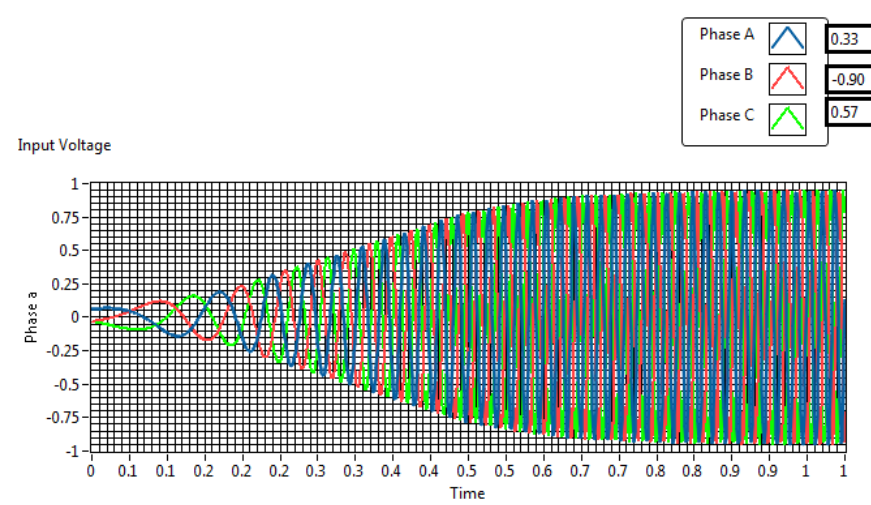

Fig. 7. Voltage source's frequency

Fig.8 illustrates the response of the induction motor under the parameters described above. To illustrate the results, we used a changeable load to affect the motor, which in our system has negative and positive repetitive step values. It can be seen that the motor has stable speed despite the load change. Even when loading the motor on start-up, the speed remained stable.

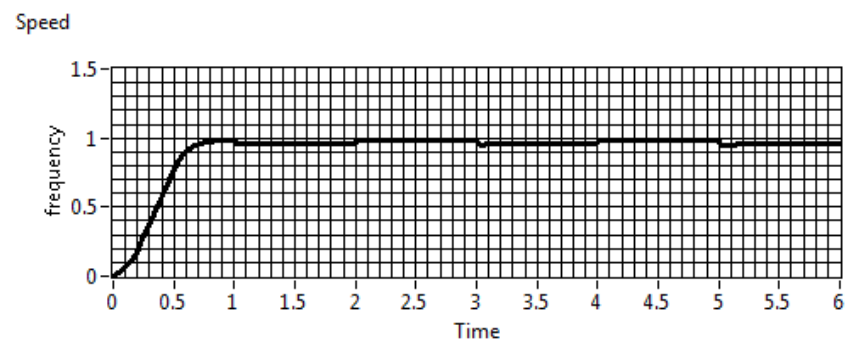

Load

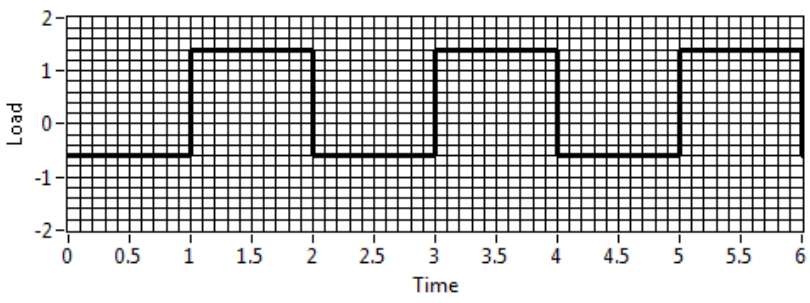

Fig. 8. System response to load change

Fig.9 shows the motor torque response to the slip change, which is also stable and has good results at the steady state. 
$\mathrm{Te}$

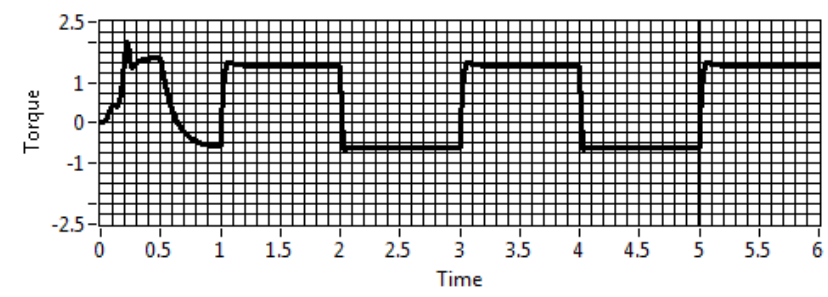

Slip Speed

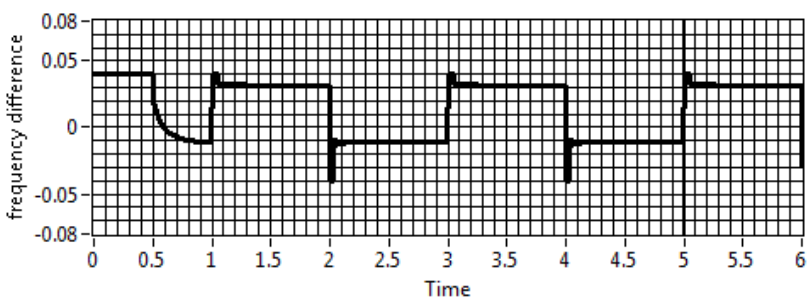

Fig. 9. Torque generated by the motor, and its response to the slip change

\section{CONCLUSION}

In this paper, the Labview software is used to model and simulate the speed control of a three phase induction motor under changeable load. To avoid magnetic saturation and optimally utilize stator and rotor core, a constant flux level is maintained constant depending on the scalar control technique. Useful methods, such as the bond graph and vector control are also used in obtaining the motor model. The simulation results show the control of the motor startup, as well as the system response to a large step-load change to keep the speed constant.

\section{REFERENCES}

[1] Hegde, S., Angadi, S. and Raju, A.B., Speed control of 3-phase induction motor using volt/hertz control for automotive application.

[2] Fathima, M.B., Princy, P.M.J. and RamPrasath, S., 2017, April. Mathematical modeling of SVPWM inverter fed 3 phase induction motor vector control in MATLAB/Simulink environment. In Circuit, Power and Computing Technologies (ICCPCT), 2017 International Conference on (pp. 1-8). IEEE.

[3] Kohlrusz, G. and Fodor, D., 2011. Comparison of scalar and vector control strategies of induction motors. Hungarian Journal of Industry and Chemistry, 39(2), pp.265-270.

[4] Brown, F.T., 2006. Engineering system dynamics: a unified graphcentered approach. CRC press.

[5] Shah, S., Rashid, A. and Bhatti, M.K.L., 2012. Direct quadrate (dq) modeling of 3-phase induction motor using matlab/simulink. Canadian Journal on Electrical and Electronics Engineering, 3(5), pp.237-243.

[6] Akin, B. and Garg, N., 2013. Scalar (V/f) control of 3-phase induction motors. Texas Instruments Incorporated, Texas.

[7] Karanayil, B., Rahman, M.F. and Grantham, C., 2000. A Complete Dynamic Model for a PWM VSI-fed rotor flux oriented vector controlled Induction Motor Drive using SIMULINK. In Power Electronics and Motion Control Conference, 2000. Proceedings. IPEMC 2000. The Third International (Vol. 1, pp. 284-288). IEEE.

[8] Chang, J.H. and Kim, B.K., 1997. Minimum-time minimum-loss speed control of induction motors under field-oriented control. IEEE transactions on industrial electronics, 44(6), pp.809-815.

[9] Shi, K.L., Chan, T.F. and Wong, Y.K., 1997, May. Modelling of the three-phase induction motor using SIMULINK. In Electric Machines and Drives Conference Record, 1997. IEEE International (pp. WB3-6). IEEE.

[10] Shaltout, A. and Youssef, O.E.M., 2017, December. Speed control of induction motors using proposed closed loop Volts/hertz control scheme. In Power Systems Conference (MEPCON), 2017 Nineteenth International Middle East (pp. 533-537). IEEE.

[11] Krause, P., Wasynczuk, O., Sudhoff, S.D. and Pekarek, S., 2013. Analysis of electric machinery and drive systems (Vol. 75). John Wiley \& Sons. 